\title{
Study of serum progranulin level and its relation to microvascular complications in subjects with type 1 diabetes mellitus
}

\section{ABSTRACT}

Background. Progranulin is expressed in various cells including adipocytes. Having an important role in inflammation, it could participate to development of diabetes and its complications. We aimed at assessing serum progranulin level in subjects with type 1 diabetes mellitus (T1DM) and its relation to microvascular complications.

Methods. 80 subjects were included: 40 subjects with T1DM with a disease duration of more than 5 years, 20 subjects with newly diagnosed T1DM, and 20 healthy subjects as a control. Microvascular complications were assessed by clinical examination and investigations.

Results. The mean serum progranulin level was significantly higher in T1DM subjects with disease duration more than 5 years $(77.2 \pm 159.8)$ and those with disease duration less than one year $(12.8 \pm 16.0)$ comparing to healthy controls $(p=0.009, p=0.032$, respectively). However, no significant difference was found in the mean serum progranulin between the two diabetic groups ( $p$ 0.883). Serum progranulin level was significantly higher in patients with retinopathy ( $p \leq 0.001)$, nephropathy $(p=0.002)$ and neuropathy $(p=0.007)$. However, in multivariate regression analy-

Address for correspondence:

Reem Mahmoud Fathalla

Internal Medicine Department, Diabetes and Metabolism Unit,

Faculty of Medicine, Alexandria University, Egypt

e-mail: reem.fathalla@yahoo.com

Clinical Diabetology 2021, 10

DOI: $10.5603 /$ DK.a2021.0009

Received: 30.09 .2020

Accepted: 28.12 .2020 sis serum progranulin was not independently associated with microvascular complications of diabetes. Conclusion. Serum progranulin is higher in T1DM than control and was not independently associated with diabetic microvascular complications. (Clin Diabetol 2021; 10)

Key words: diabetes mellitus, microvascular complications, progranulin, T1DM

\section{Introduction}

Clinically, diabetic microangiopathy is usually presented by diabetic nephropathy (DN), diabetic retinopathy (DR), and diabetic peripheral neuropathy (DPN). The mechanisms have been explained by many theories, mainly including polyol pathway [1], increased formation of advanced glycation end products (AGEs) [1], protein kinase $C$ pathway [1], non-enzymatic glycation, oxidative stress, and hexosamine biosynthesis. Studies have demonstrated that activation of inflammatory process may lead to development of diabetic microangiopathy. Activation of growth factors and adhesion molecules can stimulate the movement of inflammatory cells into renal microvasculature, predisposing to the development of diabetic nephropathy [1]. Progranulin is associated with autoimmunity and was found to be elevated in some autoimmune diseases. It was demonstrated by a recent study that progranulin is very important to antigen presenting in macrophages by binding with toll like receptor 9 (TLR9) [1]. Progranulin is a $68-88 \mathrm{kDa}$ protein which has 7.5 granulin motifs linked by short linker domains [1]. Progranulin exists 
in adipose tissue, epithelial tissue, gastrointestinal tract and reproductive organs, which is involved in cell growth and survival and inflammatory response $[1,4]$. Full length progranulin stimulates cell growth and survival and has anti-inflammatory activity [1, 2]. However, proteolytic cleavage of progranulin produces granulin peptides, some of which stimulate inflammation [1]. Moreover, progranulin in adipocytes impairs insulin signaling and promote inflammation [1]. It was found that circulating progranulin level is elevated in patients with type 2 DM [1], and is associated with impaired glucose tolerance rather than impaired fasting glucose [1]. Taken together, progranulin is an essential molecule in inflammatory response, glycometabolism, insulin resistance and could be included in chronic subclinical inflammation associated with pathogenesis of diabetic microangiopathy. However, paucity of data has been published concerning progranulin in relation to diabetic microangiopathy in type $1 \mathrm{DM}$. We therefore developed a study regarding serum level of progranulin and its relation to diabetic microvascular complications in type $1 \mathrm{DM}$.

\section{Methods. Study design}

This case control study was conducted on 80 subjects divided into three groups: group A included 40 patients with type 1 diabetes with disease duration more than 5 years who are more likely to have diabetes complications with mean age $25.9 \pm 7.1$, group B included 20 patients with newly diagnosed type 1 diabetes (disease duration less than one year) who are unlikely to have diabetes complications with mean age $25.2 \pm 5.3$ and group $C$ of age and sex matched 20 healthy subjects as a control group. T1DM subjects were recruited from the outpatient clinic of the Diabetes and metabolism unit at Alexandria Main University Hospital. The study design was approved by the ethics committee of Alexandria University. The study was conducted according to the criteria set by the declaration of Helsinki and each subject signed an informed consent before participating in the study.

Exclusion criteria: age $<18$ years, patients with type 2 DM, malignancy, acute trauma, recent inflammatory disease, degenerative disease of nervous system. Moreover, pregnant females were excluded from the study.

\section{Subjects and methods}

Clinical assessment

All study participants were subjected to a full medical history assessment and complete physical examination. BMI was calculated using the Quetelet formula (weight in $\mathrm{kg}$ divided by the height in $\mathrm{m}^{2}$ ). The waist circumference was measured at the midpoint between the lower margin of the last palpable rib and the top of the iliac crest, using a stretch-resistant tape.

\section{Assessment of diabetes microvascular complications}

To assess diabetic neuropathy, Semmes-Weinstein 10 gram monofilaments were applied to nine sites on each foot. Each site was tested three times randomly. Loss of protective sensation at a site was defined if there were two or more failures to feel the Monofilament. The test was considered positive if the subject could feel the sensation in less than 6 sites out of nine [1]. Vibration perception was assessed using the biothesiometer (Diabetica solutions Inc., USA). It was tested over the pulp of the hallux. With the patient lying supine, the stylus of the instrument was placed over the dorsal hallux and the voltage amplitude was increased until the patient can detect the vibration; the resulting number is known as the vibration perception threshold (VPT). A VPT $>25 \mathrm{~V}$ was regarded as abnormal result [1]. Diabetic neuropathy was defined if there was a positive monofilament test plus either an absent ankle reflex or a VPT > 25 V [1]. To detect diabetic retinopathy, Fundus examination was performed by an Ophthalmologist. The Urinary Albumin-to-Creatinine Ratio (UACR) was calculated and eGFR was measured using the CKD- EPI formula. Diabetic nephropathy was defined as either UACR $>30 \mathrm{mg} / \mathrm{g}$ or an eGFR $<60 \mathrm{~mL} / \mathrm{min} / 1.73 \mathrm{~m}^{2}$ [1].

\section{Biochemical analysis}

All that biochemical parameters (Fasting blood glucose, kidney function tests, e GFR) were measured by chemistry auto-analyzer Dimension RxL Max (siemens Health Care Diagnostics, USA). HbA1C was measured by Auto-analyser TOSOH (TOSOH Biosciences, USA). The determination of serum progranulin was carried by enzyme linked immunosorbent assays (ELISA).

\section{Statistical analysis}

Data were fed to the computer and analyzed using IBM SPSS software package version 20.0. (Armonk, NY: IBM Corp). Qualitative data were described using number and percent. Quantitative data were described using range (minimum and maximum), mean, standard deviation and median. Significance of the obtained results was judged at the $5 \%$ level. Chi-square test was used for categorical variables, to compare between different groups. Monte Carlo correction was used as Correction for chi-square when more than $20 \%$ of the cells have expected count less than 5. F-test (ANOVA) was used for normally distributed quantitative variables, to compare between more than two groups, and post hoc test (Tukey) for pairwise comparisons. Mann 
Table 1. Comparison between the different studied groups according to demographic data

\begin{tabular}{|c|c|c|c|c|c|c|c|c|}
\hline & \multicolumn{2}{|c|}{ Group A $(n=40)$} & \multicolumn{2}{|c|}{ Group B $(n=20)$} & \multicolumn{2}{|c|}{ Group C $(n=20)$} & \multirow[t]{2}{*}{ Test of significance } & \multirow[t]{2}{*}{$\mathbf{P}$} \\
\hline & No. & $\%$ & No. & $\%$ & No. & $\%$ & & \\
\hline \multicolumn{9}{|l|}{ Sex } \\
\hline Male & 17 & 42.5 & 9 & 45.0 & 13 & 65.0 & $\chi^{2}=2.9$ & 0.240 \\
\hline Female & 23 & 57.5 & 11 & 55.0 & 7 & 35.0 & & \\
\hline \multicolumn{9}{|l|}{ Age [years] } \\
\hline Mean \pm SD & $25.9 \pm 7.1$ & & $25.2 \pm 5.3$ & & $31.6 \pm 12.8$ & $\mathrm{H}=2.5$ & 0.286 & \\
\hline Median & 22.5 & & 23.5 & & 29.0 & & & \\
\hline Hypertension & & & & & & & $\chi^{2}$ & $M C_{p}$ \\
\hline Negative & 37 & 92.5 & 20 & 100.0 & 17 & 58.0 & 2.9 & 0.210 \\
\hline Positive & 3 & 7.5 & 0 & 0.0 & 3 & 15.0 & & \\
\hline Duration of DM (years) & & & & & & & $u$ & $P$ \\
\hline Mean \pm SD & $11.8 \pm 7.1$ & & $0.2 \pm 0.3$ & & & & $0.000^{*}$ & $<0.001^{*}$ \\
\hline Median & 10.0 & & 0.1 & & & & & \\
\hline \multicolumn{9}{|l|}{ BMI $\left[\mathrm{kg} / \mathrm{m}^{2}\right]$} \\
\hline Mean \pm SD & $24.5 \pm 3.3$ & $22.8 \pm 2.7$ & & $22.8 \pm 2.7$ & & $F=2.9$ & 0.056 & \\
\hline Median & 25.0 & & 22.0 & & 22.0 & & & \\
\hline \multicolumn{9}{|l|}{ Waist circumference $[\mathrm{cm}]$} \\
\hline \multirow[t]{2}{*}{ Mean \pm SD } & $95.0 \pm 8.4$ & $96.5 \pm$ & & $96.5 \pm$ & & $\mathrm{H}=2.5$ & 0.290 & \\
\hline & & 23.2 & & 23.2 & & & & \\
\hline Median & 96.5 & & 90.0 & & 90.0 & & & \\
\hline
\end{tabular}

$\chi^{2}$ - Chi square test; MC - Monte Carlo; $\mathrm{U}$ - Mann Whitney test; $\mathrm{H}-\mathrm{H}$ for Kruskal Wallis test, Pairwise comparison between each 2 groups was done using Post Hoc Test (Dunn's for multiple comparisons test); $\mathrm{F}-\mathrm{F}$ for ANOVA test, pairwise comparison between each 2 groups was done using post hoc test (Tukey); $p-p$ value for comparing between the three studied groups; $p_{1}-p$ value for comparing between group $A$ and $B ; p_{2}-p$ value for comparing between group $A$ and $C ; p_{3}-p$ value for comparing between group $B$ and $C ;$ Sig. bet. groups - significance between groups

Whitney test was used for abnormally distributed quantitative variables, to compare between two studied groups and Kruskal Wallis test was used for abnormally distributed quantitative variables, to compare between more than two studied groups. Regression analysis was used to detect the most independent/ affecting factor for retinopathy, neuropathy and nephropathy.

\section{Results}

\section{Demographic data}

Table 1. shows the baseline characteristic of the studied population. There was no significant difference in terms of male/female ratio, age, BMI and waist circumference. The mean disease duration was $11.8 \pm$ 7.1 and $0.2 \pm 0.3$ in group $A$ and $B$ respectively.

\section{Microvascular complications}

As regards the prevalence of microvascular diabetes complications in group A, $47 \%$ of patients had diabetic peripheral neuropathy, $27.5 \%$ had retinopathy and $57.5 \%$ of patients had diabetic nephropathy. All patients in group B were free from diabetes complications.

\section{Laboratory investigations and serum progranulin level}

As shown in Table 2 FPG, HbA1C and serum creatinine were significantly higher in group $A$. Serum progranulin level was significantly higher in group $A$ and $B$ than $C$, while no statistically significant difference between group $A$ and $B$.

\section{Correlation between serum progranulin level} with different studied clinical and biochemical parameters in group A and B

In group A there was significant positive correlation between duration of DM ( $p<0.001^{*}$, $r=0.537)$ and VPT $\left(p<0.001^{*}, r=0.667^{*}\right)$ with serum progranulin, while a significant negative correlation was observed between GFR and serum progranulin ( $\left.p 0.006^{*}, r=-0.424\right)$. On the other hand, we found no correlation between serum progranulin with age, BMI, waist circumference and HbA1C. In group B, no significant correlation was found between serum progranulin and any of the studied parameters. 
Table 2. Comparison between the different studied groups according to laboratory investigations

\begin{tabular}{|c|c|c|c|c|c|}
\hline & Group A $(n=40)$ & Group B $(n=20)$ & Group C $(n=20)$ & Test of signifi-cance & $\mathbf{P}$ \\
\hline \multicolumn{6}{|l|}{$\mathrm{FBS}[\mathrm{mg} / \mathrm{dL}]$} \\
\hline Mean \pm SD & $151.4 \pm 31.4$ & $180.4 \pm 81.2$ & $88.1 \pm 7.4$ & $\mathrm{H}=44.7^{*}$ & $<0.001^{*}$ \\
\hline Median & 146.0 & 150.5 & 88.0 & & \\
\hline Sig. bet. Groups & \multicolumn{5}{|c|}{$\mathrm{p} 1=0.646, \mathrm{p} 2<0.001^{*}, \mathrm{p} 3<0.001^{*}$} \\
\hline \multicolumn{6}{|l|}{$\mathrm{HB} A 1 \mathrm{C}[\%]$} \\
\hline Mean \pm SD & $8.7 \pm 1.2$ & $7.2 \pm 0.6$ & $6.0 \pm 0.5$ & $F=61.12^{*}$ & $<0.001 *$ \\
\hline Median & 8.5 & 7.0 & 6.0 & & \\
\hline Sig. bet. Groups & \multicolumn{5}{|c|}{$\mathrm{p} 1<0.001^{*}, \mathrm{p} 2<0.001^{*}, \mathrm{p} 3=0.001^{*}$} \\
\hline \multicolumn{6}{|c|}{ Creatinine (mg/dL) } \\
\hline Mean \pm SD & $1.4 \pm 1.1$ & $0.8 \pm 0.2$ & $1.0 \pm 0.1$ & $H=17.2^{*}$ & $<0.001 *$ \\
\hline Median & 1.2 & 0.8 & 1.0 & & \\
\hline Sig. bet. Groups & \multicolumn{5}{|c|}{$\mathrm{p} 1<0.001^{*}, \mathrm{p} 2<0.001^{*}, \mathrm{p} 3=0.087$} \\
\hline \multicolumn{6}{|c|}{ Progranulin (ng/mL) } \\
\hline Mean \pm SD & $77.2 \pm 159.8$ & $12.8 \pm 16.0$ & $10.4 \pm 18.7$ & $\mathrm{H}=7.5^{*}$ & $0.024^{*}$ \\
\hline Median & 9.6 & 9.3 & 2.4 & & \\
\hline Sig. bet. grps. & \multicolumn{5}{|c|}{$p 10.883, p 2=0.009^{*}, p 3=0.032^{*}$} \\
\hline
\end{tabular}

$\mathrm{H}-\mathrm{H}$ for Kruskal Wallis test, Pairwise comparison between each 2 groups was done using Post Hoc Test (Dunn's for multiple comparisons test); $\mathrm{F}-\mathrm{F}$ for ANOVA test, Pairwise comparison between each 2 groups was done using post hoc test (Tukey); $p-p$ value for comparing between the three studied groups; $p_{1}-p$ value for comparing between group $A$ and $B ; p_{2}-p$ value for comparing between group $A$ and $C ; p_{3}-p$ value for comparing between group B and C; Sig. bet. Groups — significance between groups

Table 3. Relation between serum progranulin and microvascular complications in group A

\begin{tabular}{|c|c|c|c|c|}
\hline Group A & $\mathrm{N}$ & Progranulin (mean \pm SD) & Test of significance & $p$ \\
\hline Cases with retinopathy & 11 & $228.1 \pm 248.5$ & $U=35.0$ & $<0.001$ \\
\hline Cases without retinopathy & 29 & $19.9 \pm 34.3$ & & \\
\hline \multicolumn{5}{|l|}{ Degree of retinopathy } \\
\hline Normal fundus & 29 & $19.9 \pm 34.3$ & $H=14.9^{*}$ & $0.001^{*}$ \\
\hline Non proliferative retinopathy & 5 & $19.9 \pm 34.3$ & & \\
\hline Proliferative retinopathy & 6 & $132.8 \pm 207.3$ & & \\
\hline Cases with nephropathy & 23 & $124.0 \pm 198$ & $U=84.0$ & 0.002 \\
\hline Cases without nephropathy & 17 & $13.9 \pm 30.5$ & & \\
\hline \multicolumn{5}{|l|}{ Degree of albuminuria } \\
\hline Normal & 19 & $15.8 \pm 30.4$ & $H=15.9^{*}$ & $<0.001^{*}$ \\
\hline Moderately increase albuminuria & 14 & $29.1 \pm 36.1$ & & \\
\hline Severely increase albuminuria & 7 & $339.9 \pm 250.2$ & & \\
\hline Cases with neuropathy & 19 & $144.6 \pm 212.7$ & $U=100.0^{*}$ & 0.007 \\
\hline Cases without neuropathy & 21 & $16.2 \pm 29.2$ & & \\
\hline
\end{tabular}

$\mathrm{U}-$ Mann Whitney test; $\mathrm{H}-\mathrm{H}$ for Kruskal Wallis test. *Statistically significant at $\mathrm{p} \leq 0.05$

Relation between serum progranulin and microvascular complications in group A

Serum progranulin levels were significantly higher in patients with retinopthy $(p<0.001)$, nephropathy $(p=0.002)$ and neuropathy $(p=0.007)$ than those without complications. Moreover, patients with proliferative retinopathy had a significantly higher level of serum progranulin than those with non-proliferative retinopathy. In addition, serum progranulin level was significantly higher in patients with severely increased albuminuria than patients with moderately increased albuminuria (Table 3).

\section{Regression analysis of microvascular complication risk factors}

Multivariate regression analysis was performed to determine the influence of independent factors identified in Univariate regression analysis including age, 
Table 4. Univariate and multivariate analysis for the parameters affecting (nephropathy) at group A

\begin{tabular}{|c|c|c|c|c|}
\hline \multirow[t]{2}{*}{ Nephropathy } & \multicolumn{2}{|l|}{ Univariate } & \multicolumn{2}{|l|}{ Multivariate ${ }^{\#}$} \\
\hline & OR (95\%C.I) & $\mathbf{P}$ & OR $(95 \% \mathrm{Cl})$ & $\mathbf{P}$ \\
\hline Age (years) & $1.1^{*}(1.0-1.3)$ & $0.049^{*}$ & $1.1(0.9-1.3)$ & 0.616 \\
\hline Sex (females) & $1.4(0.4-4.9)$ & 0.616 & & \\
\hline Waist & $1.0(0.9-1.0)$ & 0.331 & & \\
\hline BMI & $0.9(0.8-1.2)$ & 0.601 & & \\
\hline $\mathrm{HbA1c}$ & $1.7(0.9-3.3)$ & 0.099 & & \\
\hline Duration of diabetes & $1.8^{*}(1.2-2.6)$ & $0.002^{*}$ & $1.8^{*}(1.2-2.6)$ & $0.003^{*}$ \\
\hline HTN & - & 0.999 & & \\
\hline Progranulin [ng/mL] & $1.0(1.0-1.1)$ & 0.099 & & \\
\hline
\end{tabular}

$\mathrm{OR}$ - odd's ratio; $\mathrm{Cl}$ - confidence interval. \#All variables with $\mathrm{p}<0.05$ was included in the multivariate. *Statistically significant at $\mathrm{p} \leq 0.05$

Table 5. Univariate and multivariate analysis for the parameters affecting retinopathy at group A

\begin{tabular}{lcccc}
\hline Retinopathy & Univariate & & ${ }^{\text {\#Multivariate }}$ \\
\cline { 2 - 4 } & OR $(95 \% \mathrm{Cl})$ & $\mathbf{P}$ & OR $(95 \% \mathrm{Cl})$ & $\mathbf{P}$ \\
\hline Age [years] & $1.2^{*}(1.0-1.3)$ & $0.008^{*}$ & $0.9(0.6-1.3)$ & 0.552 \\
Sex [females] & $1.4(0.3-5.9)$ & 0.629 & & \\
Waist & $0.9(0.9-1.0)$ & 0.214 & & $0.021^{*}$ \\
BMI [kg/m²] & $0.9(0.7-1.1)$ & 0.393 & $2.8^{*}(1.2-6.9)$ & \\
HbA1c & $3.3^{*}(1.4-8.0)$ & $0.008^{*}$ & & \\
Duration of diabetes & $2.7^{*}(1.1-6.3)$ & $0.024^{*}$ & & \\
HTN & - & 0.999 & & \\
Progranulin [ng/mL] & $1.0(1.0-1.0)$ & 0.066 & & \\
\hline
\end{tabular}

$\mathrm{OR}$ - odd's ratio; $\mathrm{Cl}$ - confidence interval. \#All variables with $\mathrm{p}<0.05$ was included in the multivariate; *Statistically significant at $\mathrm{p} \leq 0.05$

Table 6. Univariate and multivariate analysis for the parameters affecting neuropathy at group A

\begin{tabular}{|c|c|c|c|c|}
\hline \multirow[t]{2}{*}{ Neuropathy } & \multicolumn{2}{|c|}{ Univariate } & \multicolumn{2}{|c|}{ Multivariate\# } \\
\hline & OR $(95 \% \mathrm{Cl})$ & $\mathbf{P}$ & OR $(95 \% \mathrm{Cl})$ & $\mathbf{P}$ \\
\hline Age [years] & $1.1 *(1.0-1.2)$ & $0.047^{*}$ & $1.0(0.8-1.1)$ & 0.615 \\
\hline Sex [females] & $2.4(0.7-8.7)$ & 0.188 & & \\
\hline Waist & $1.0(0.9-1.1)$ & 0.481 & & \\
\hline BMI & $1.0(0.8-1.2)$ & 0.965 & & \\
\hline HbA1c & $1.5(0.8-2.7)$ & 0.190 & & \\
\hline Duration of diabetes & $1.6^{*}(1.2-2.0)$ & $0.002^{*}$ & $1.6^{*}(1.2-2.1)$ & $0.002 *$ \\
\hline HTN & $2.4(0.2-28.3)$ & 0.500 & & \\
\hline Progranulin [ng/mL] & $1.0(1.0-1.0)$ & 0.087 & & \\
\hline
\end{tabular}

$\mathrm{OR}$ - odd's ratio; $\mathrm{Cl}$ - confidence interval. \#All variables with $\mathrm{p}<0.05$ was included in the multivariate; *5Statistically significant at $\mathrm{p} \leq 0.05$

HbA1C and duration of DM. The analysis demonstrated that only duration of DM was positively associated with microvascular complications (Tables 4-6).

\section{Discussion}

Progranulin is an important multifunctional protein, which has been implicated in cell growth, wound repair, tumorigenesis, neurodevelopment, neurodegeneration, and more recently inflammation. Recent studies in the last decade have shown that inflammation is a key process in the development of diabetes mellitus and diabetic microangiopathy. In this context, progranulin, caught our attention, because it is a kind of adipocytokines with important functions in modulation 
of inflammatory events. There are multiple studies that discussed the relation between serum progranulin and microvascular complications associated with type $2 \mathrm{DM}$ [1]. On the other hand, the role of serum progranulin in type 1 diabetic microangiopathy has not been well investigated.

\section{Association between serum progranulin and DM}

Serum progranulin level is usually low, being up regulated in the inflammatory state suggesting its involvement in chronic subclinical inflammation associated with the pathogenesis of diabetic microangiopathy. In this study, we tried to find out the possibility of using serum progranulin as a biomarker for diabetic microvascular complications in type 1 diabetes [1]. To our knowledge, there are no studies done on subjects with type $1 \mathrm{DM}$ to assess serum progranulin level and its relation to microvascular complications. A study was conducted by Albeltagy et al to evaluate serum progranulin as a biomarker for presence and severity of microvascular complications in type 2 DM. They conducted their cross sectional study in 2019 on 90 participants. They found that serum progranulin levels were significantly higher in patients with type 2 diabetes than healthy controls with the highest levels in those with microvascular complications [1]. Another study was done by Ezz et al on 60 subjects classified as: 20 diabetic patients with nephropathy, 20 diabetic patients with normal kidney function and 20 normal controls [1]. They found that serum levels of progranulin were high in type 2 diabetic patients with significantly higher values detectable in clinical diabetic nephropathy. This finding is consistent with $\mathrm{Xu}$ et al. results who conducted their study on 84 type 2 diabetic patients with and without microvascular complications and 12 healthy controls. They aimed to investigate the correlation between progranulin and type 2 diabetics with microvascular complications [1]. They noticed that serum levels of progranulin were markedly higher in type 2 diabetic patients with microangiopathies. Similar results were observed by Qu et al. who conducted their study on eighty patients with newly diagnosed type 2 diabetes and 88 subjects with normal glucose tolerance to assess the concentrations of serum progranulin in Chinese patients with obesity and type 2 diabetes mellitus [1]. They found that serum progranulin level was significantly higher in type 2 diabetic patients with metabolic syndrome than healthy controls. In agreement with the previous results, a study conducted by Shafaei et al. included 60 patients with type 2 diabetes and 30 healthy individuals as control group to assess the serum progranulin level of in type 2 diabetic patients with and without metabolic syndrome and compare them with healthy controls [2]. They found that serum level of progranulin had slightly increased in type 2 diabetic patients with metabolic syndrome; this elevation was not statistically significant. Furthermore, Youn et al. conducted their cross sectional study on 269 Korean individuals for assessment of serum progranulin concentrations in relation to measures of obesity and glucose metabolism [1]. They found that serum level of progranulin was high in type 2 diabetic subjects compared to normal subjects. More recently, Zaky et al. have shown similar results in a cohort of type 2 diabetic subjects [1].

\section{Progranulin and nephropathy}

Microvascular complications of T1DM are associated with severe morbidity, mortality and a huge economic burden. So, there is an important need to identify new biomarker able to identify disease onset and progression and can be used as a therapeutic target for management of these complications. To clarify the relationship between the increased serum progranulin and the development of diabetic microvascular complications, we further tested serum progranulin levels in patients with different stages of diabetic nephropathy. We found that serum progranulin level was significantly higher in patients with nephropathy (albuminuria $>30$ $\mathrm{mg} / 24 \mathrm{~h}$ and/or GFR $<60 \mathrm{~mL} / \mathrm{min} / 1.73 \mathrm{~m}^{2}$ ). As regard albuminuria we found that there was no statistically significant difference between patients with normoalbuminuria and patients with moderately increase albuminuria regarding serum progranulin while there was a statistically significant difference between patients with normoalbuminuria and patients with severely increase albuminuria. Also there was a statistically significant difference between patients with moderately increase albuminuria and patients with severely increase albuminuria. As regard GFR, we found significant negative correlation between GFR and serum progranulin in group A. However, univariate regression analysis of factors that may affect nephropathy showed that serum progranulin was not an independent risk factor. The only study in type 1 DM was done by Schlatzer et al who conducted their study on seventy-four patients with type 1 diabetes [7]. Subjects were evaluated and urine collected at baseline, and after 6 years, when albuminuria and early renal function decline (ERFD, defined as a decline in cystatin C-based estimated GFR of $\geq 3.3 \%$ per year). Patients with both ERFD and albuminuria presented higher urinary progranulin levels at baseline than patients who maintained normal renal function and normoalbuminuria, when adjusted by age, diabetes duration, baseline albumin excre- 
tion rate, $\mathrm{HbA} 1 \mathrm{C}$, cystatin $\mathrm{C}$ and uric acid. Moreover, progranulin was significantly predictive of ERFD and albuminuria in patients with type 1 diabetes in multivariable logistic regression [1]. In accordance with our study, aforementioned study of Albeltagy et al found that serum PRGN level was significantly higher in diabetics with macro-albuminuria compared with diabetics with microalbuminuria and diabetics without albuminuria. On the other hand they found that serum progranulin was significantly higher in diabetics with microalbuminuria compared with diabetics without albuminuria. Also they found significant negative correlation between GFR and serum progranulin which is similar to our results [3].

In agreement with our study, the previously mentioned study of Xu et al. found that serum progranulin levels did not differ distinctly between diabetics without albuminuria and with microalbuminuria but found that serum progranulin was significantly increased in the macroalbuminuric group [1]. Furthermore, our results were supported by Richter et al. who conducted their study on 532 patients (205 of them were diabetics) with stages $1-5$ of CKD (according to the National Kidney Foundation classification) and they had their PGRN serum levels evaluated. Even after adjustment for age, sex and BMI, PGRN remained significantly different between the five subgroups of CKD, being higher in stage 5. Moreover, estimated GFR was identified as an independent predictor of progranulin circulating levels. These findings suggest that renal filtration is an important route of PGRN elimination [1] suggesting progranulin as a marker for diabetic microangiopathy and its severity [1]. Most recently, Zaky et al. have shown higher levels of progranulin in type 2 diabetic subjects with microangiopathy than those without [24].

\section{Progranulin and retinopathy}

We found that in group $A$ there were 11 patients ( $27.5 \%)$ have retinopathy and 29 patients $(72.5 \%)$ have normal fundus examination. There was statistically significant difference between patients with or without retinopathy regarding serum level of progranulin. When considering severity of diabetic retinopathy, there was no statistically significant difference between diabetic patients with normal fundus examination and diabetic patients with non-proliferative retinopathy regarding serum progranulin but serum Progranulin in patients with proliferative retinopathy was significantly higher than patients with normal fundus examination and with non-proliferative retinopathy. However, univariate regression analysis of factors that may affect retinopathy showed that serum progranulin was not independent risk factor. In accordance with our study, the previously mentioned study of Albeltagy et al. found that Serum progranulin was significantly elevated in diabetic patients with DR compared to those without DR. When considering severity of $D R$, the serum progranulin level was significantly higher in the PDR group, compared with NPDR groups [3]. In agreement with our study, aforementioned study of $\mathrm{Xu}$ et al found that serum progranulin levels did not differ distinctly between diabetics without retinopathy and non-proliferative retinopathy but found that serum progranulin was significantly increased in the proliferative retinopathy group than controls and diabetics without retinopathy [1].

\section{Progranulin and neuropathy}

The current study found that there was positive correlation between VPT and progranulin which is statistically significant in group $\mathrm{A}$. We found that in group A there were 19 patients (47.5\%) have neuropathy with mean value of serum progranulin $144.6 \pm 212.7$. There was statistically significant difference between patients with or without neuropathy regarding serum level of progranulin. However, univariate regression analysis of factors that may affect neuropathy showed that serum progranulin was not independent risk factor. Studies about progranulin and diabetic neuropathy are rare. To our knowledge only one study assessed serum progranulin and its relation to diabetic neuropathy. This study was previously mentioned with Albeltagy et al. who found that serum progranulin was significantly elevated in diabetic patients with diabetic neuropathy compared to those without [3].

\section{Conclusion}

Serum progranulin level is higher in subjects with T1DM. However, it was not associated with the presence of microvascular complications.

\section{Conflict of interest}

We wish to confirm that there are no known conflicts of interest associated with this publication and there has been no significant financial support for this work that could have influenced its outcome.

\section{REFERENCES}

1. Dunlop M. Aldose reductase and the role of the polyol pathway in diabetic nephropathy. Kidney Int Suppl. 2000; 58: 77-89, doi: 10.1046/j.1523-1755.2000.07702.x, indexed in Pubmed: 10997684.

2. Forbes JM, Thallas V, Thomas MC, et al. The breakdown of preexisting advanced glycation end products is associated with reduced renal fibrosis in experimental diabetes. FASEB J. 2003; 17(12): 1762-1764, doi: 10.1096/fj.02-1102fje, indexed in Pubmed: 12958202.

3. Koya D, Jirousek MR, Lin YW, et al. Characterization of protein kinase $\mathrm{C} \beta$ isoform activation on the gene expression of trans- 
forming growth factor- $\beta$, extracellular matrix components, and prostanoids in the glomeruli of diabetic rats. Journal of Clinical Investigation 1997; 100: 115-126.

4. Galkina $E$, Ley K. Leukocyte recruitment and vascular injury in diabetic nephropathy. J Am Soc Nephrol. 2006; 17(2): 368-377, doi: 10.1681/ASN.2005080859, indexed in Pubmed: 16394109.

5. Park B, Buti L, Lee $S$, et al. Granulin is a soluble cofactor for tolllike receptor 9 signaling. Immunity. 2011; 34(4): 505-513, doi: 10.1016/j.immuni.2011.01.018, indexed in Pubmed: 21497117.

6. He Z, Bateman A. Progranulin (granulin-epithelin precursor, PCcell-derived growth factor, acrogranin) mediates tissue repair and tumorigenesis. J Mol Med (Berl). 2003; 81(10): 600-612, doi: 10.1007/s00109-003-0474-3, indexed in Pubmed: 12928786.

7. Tolkatchev D, Malik S, Vinogradova A, et al. Structure dissection of human progranulin identifies well-folded granulin/epithelin modules with unique functional activities. Protein Sci. 2008; 17(4): 711-724, doi: 10.1110/ps.073295308, indexed in Pubmed: 18359860.

8. Jones MB, Spooner M, Kohn EC. The granulin-epithelin precursor: a putative new growth factor for ovarian cancer. Gynecol Oncol. 2003; 88(1 Pt 2): S136-S139, doi: 10.1006/gyno.2002.6704, indexed in Pubmed: 12586105.

9. Pizarro GO, Zhou XC, Koch A, et al. Prosurvival function of the granulin-epithelin precursor is important in tumor progression and chemoresponse. Int J Cancer. 2007; 120(11): 2339-2343, doi: 10.1002/ijc.22559, indexed in Pubmed: 17266030.

10. Zhu J, Nathan C, Jin W, et al. Conversion of proepithelin to epithelins: roles of SLPI and elastase in host defense and wound repair. Cell. 2002; 111(6): 867-878, doi: 10.1016/s0092-8674(02)011418, indexed in Pubmed: 12526812.

11. Matsubara T, Mita A, Minami K, et al. PGRN is a key adipokine mediating high fat diet-induced insulin resistance and obesity through IL-6 in adipose tissue. Cell Metab. 2012; 15(1): 38-50, doi: 10.1016/j.cmet.2011.12.002, indexed in Pubmed: 22225875.

12. Youn BS, Bang SI, Klöting N, et al. Serum progranulin concentrations may be associated with macrophage infiltration into omental adipose tissue. Diabetes. 2009; 58(3): 627-636, doi: 10.2337/db08-1147, indexed in Pubmed: 19056610.

13. Tönjes A, Fasshauer M, Kratzsch J, et al. Adipokine pattern in subjects with impaired fasting glucose and impaired glucose tolerance in comparison to normal glucose tolerance and diabetes. PLoS One. 2010; 5(11): e13911, doi: 10.1371/journal. pone.0013911, indexed in Pubmed: 21085476.

14. Kamei N, Yamane K, Nakanishi S, et al. Effectiveness of SemmesWeinstein monofilament examination for diabetic peripheral neuropathy screening. J Diabetes Complications. 2005; 19(1): 47-53, doi: 10.1016/j.jdiacomp.2003.12.006, indexed in Pubmed: 15642490 .

15. Armstrong DG, Lavery LA, Vela SA. Choosing a Practical Screening Instrument to Identify Patients at Risk for Diabetic Foot UI- ceration. Arch Intern Med. 1998; 158(3): 289-292, doi: 10.1001/ archinte.158.3.289.

16. Boulton AJM, Armstrong DG, Albert SF, et al. Comprehensive foot examination and risk assessment: a report of the task force of the foot care interest group of the American Diabetes Association, with endorsement by the American Association of Clinical Endocrinologists. Diabetes Care. 2008; 31(8): 1679-1685, doi: 10.2337/dc08-9021, indexed in Pubmed: 18663232.

17. American Diabetes Association. Classification and diagnosis of diabetes. Standards of Medical Care in Diabetes. Diabetes Care. 2014; 37(Suppl 1).

18. Xu L, Zhou Bo, Li H, et al. Serum levels of progranulin are closely associated with microvascular complication in type 2 diabetes. Dis Markers. 2015; 2015: 357279, doi: 10.1155/2015/357279, indexed in Pubmed: 26106251.

19. Shafaei A, Marjani A, Khoshnia M. Serum Progranulin Levels in Type 2 Diabetic Patients with Metabolic Syndrome. Romanian Journal of Internal Medicine. 2016; 54(4): 211-216, doi: 10.1515/ rjim-2016-0034.

20. Albeltagy ES, Hammour AE, Albeltagy SA. Potential value of serum Progranulin as a biomarker for the presence and severity of micro vascular complications among Egyptian patients with type 2 diabetes mellitus. J Diabetes Metab Disord. 2019; 18(1): 217-228, doi: 10.1007/s40200-019-00406-1, indexed in Pubmed: 31275893.

21. Assessment of progranulin in egyptian type 2 diabetic patients as a novel biomarker for diabetic nephropathy. International Journal of Biosciences (IJB). 2016; 9(6): 350-359, doi: 10.12692/ ijb/9.6.350-359.

22. Qu H, Deng $H, H u Z$. Plasma progranulin concentrations are increased in patients with type 2 diabetes and obesity and correlated with insulin resistance. Mediators Inflamm. 2013; 2013: 360190, doi: 10.1155/2013/360190, indexed in Pubmed: 23476101.

23. Youn BS, Bang SI, Klöting N, et al. Serum progranulin concentrations may be associated with macrophage infiltration into omental adipose tissue. Diabetes. 2009; 58(3): 627-636, doi: 10.2337/db08-1147, indexed in Pubmed: 19056610.

24. Zaky DS, Ahmed KY, Abd-Rabo SA, et al. Serum level of progranulin and microvascular complication in type 2 diabetes. International Journal of Diabetes Research. 2018; 7(3): 57-62.

25. Schlatzer D, Maahs DM, Chance MR, et al. Novel urinary protein biomarkers predicting the development of microalbuminuria and renal function decline in type 1 diabetes. Diabetes Care. 2012; 35(3): 549-555, doi: 10.2337/dc11-1491, indexed in Pubmed: 22238279.

26. Richter J, Focke D, Ebert T, et al. Serum levels of the adipokine progranulin depend on renal function. Diabetes Care. 2013; 36(2): 410-414, doi: 10.2337/dc12-0220, indexed in Pubmed: 23033238. 